\title{
Modos individuais e coletivos de produzir a inovação no ensino de gramática em sala de aula ${ }^{1}$
}

\author{
Individual and collective ways to produce \\ innovation on grammar teaching in the \\ classroom
}

Ana Sílvia Moço Aparício*

Universidade Municipal de São Caetano do Sul - USCS

São Caetano do Sul - Sao Paulo/Brasil

RESUMO: Neste artigo, apresentamos como a inovação é produzida em aulas de gramática de sete professores da rede pública estadual da região noroeste do estado de São Paulo que estão buscando transformar sua prática de ensino de língua portuguesa. Mobilizando referenciais teóricos de diferentes disciplinas, na tentativa de não reduzir e não fragmentar nosso objeto de investigação e utilizando a metodologia qualitativo-interpretativista de natureza etnográfica, para a geração e análise dos dados, constatamos que, embora os diferentes modos de inovação produzidos nas aulas analisadas sejam constituídos por uma interrelação de atividades e práticas múltiplas e heterogêneas, os professores que estão tentando inovar sua prática produzem algumas respostas comuns às demandas de inovação.

PALAVRAS-CHAVE: inovação na sala de aula, ensino de gramática, formação de professores.

ABSTRACT: The present paper aims at discussing how innovation is produced by teachers that are trying to transform their practice in grammar classes that take place at the Ensino Fundamental II $\left(5^{\text {th }}\right.$ to $8^{\text {th }}$ grade $)$ of state public schools in São Paulo. We mobilized theoretical basis from different disciplines, in order not to reduce and not to fragment our object of investigation; we also made use of the qualitative-interpretive methodology of ethnographic nature for the data generation and analysis. We found out that the different ways of innovating produced in the classes analyzed are constituted by the interrelation of multiple activities and practices; on the other hand, we found out that the teachers that are trying to innovate their practice produce some shared answers to the demand of innovation. KEYWORDS: innovation in the classroom, grammar teaching, teacher training.

\footnotetext{
${ }^{1}$ Este trabalho faz parte de pesquisa de doutorado realizada no departamento de Linguística Aplicada do Instituto de Estudos da Linguagem na UNICAMP, sob a orientação da Professora Inês Signorini.

* anaparicio@uol.com.br
} 


\section{Introdução}

Desde a década de 1980, com o movimento de renovação do ensino de Língua Portuguesa no Brasil, têm surgido muitos questionamentos sobre o ensino de gramática que vão desde a validade desse ensino até qual(is) concepção (ões) de gramática ensinar na escola. De qualquer modo, as discussões sempre giram em torno de alternativas oferecidas pela Linguística para a renovação do ensino de gramática na escola. Muitas dessas alternativas foram incorporadas pelos documentos oficiais - num primeiro momento, pelas Propostas Curriculares estaduais; num segundo momento, pelos Parâmetros Curriculares Nacionais (doravante PCN) - compondo um eixo do ensino da língua, que inclui aspectos relacionados ao ensino de gramática, comumente chamado de eixo da reflexão sobre a linguagem ou da prática de análise linguística. Os conteúdos indicados para as práticas desse eixo, como bem ressalta Rojo (2000, p. 32),

exigem uma compreensão mais acurada dos professores e implicam uma rediscussão do ensino de gramática em geral e, em particular, do que se tem chamado de gramática funcional ou gramática no texto ou ainda das ditas atividades epilinguísticas e metalinguísticas.

A nosso ver, essa rediscussão deve se pautar, antes de tudo, pela compreensão de como essas noções vêm sendo incorporadas pelo professor em sua prática pedagógica, ou melhor, de como a inovação trazida ou inspirada pelas orientações oficiais vem sendo produzida pelos professores na sala de aula. Tendo isso em vista, nos propusemos a investigar, em uma pesquisa mais ampla, como a inovação é produzida na sala de aula por professores empenhados em transformar sua prática pedagógica de ensino de gramática.

No presente artigo, apresentamos e discutimos resultados parciais desse trabalho, mais especificamente os resultados da análise das aulas que compõem nosso corpus de pesquisa. Para isso, organizamos o artigo em quatro seções. $\mathrm{Na}$ primeira seção, apresentamos como construímos os pressupostos teóricos da investigação. Na segunda seção, descrevemos a metodologia e o processo de geração dos dados da pesquisa. Na terceira seção, apresentamos a caracterização dos professores participantes da pesquisa e, na quarta seção, tratamos dos modos como a inovação é produzida na sala de aula por esses professores. Finalizamos o artigo com as conclusôes referentes aos resultados da análise das aulas. 


\section{A construção dos pressupostos teóricos da investigação}

O trabalho do professor em sala de aula, mais especificamente a produção da inovação do ensino de gramática pelo professor em sala de aula, é uma realidade social constituída histórica e localmente por uma heterogeneidade de saberes, crenças e valores, e por atores plurais produzidos por produtores de relaçôes sociais variadas.

$\mathrm{Na}$ tentativa, então, de apreender essa realidade social complexa, inspiramo-nos nas abordagens que compreendem o ensino como trabalho. São abordagens que buscam apreender a atividade de ensino como uma combinação de várias lógicas e temporalidades. Nos termos de Amigues (2004, p.45), a atividade de ensino

pode ser considerada o ponto de encontro de várias histórias (da instituição, do ofício, do indivíduo, do estabelecimento...), ponto a partir do qual o professor vai estabelecer relações com as prescrições, com as ferramentas, com a tarefa ${ }^{2}$ a ser realizada, com os outros (seus colegas, a administração, os alunos...), com os valores e consigo mesmo.

Desse modo, podemos entender, conforme a metáfora apresentada por Saujat (2004, p. 29), que os professores em seu trabalho tecem: nesse tecer, há os fios que os ligam aos programas e instruções oficiais, às ferramentas / instrumentos pedagógicos, às políticas educacionais, às características dos estabelecimentos de ensino e dos alunos, às regras formais, ao controle exercido pela hierarquia; assim como os fios que os ligam a sua própria história, a seu corpo que aprende e envelhece, a uma imensa quantidade de experiências de trabalho e de vida, a vários grupos sociais que lhes oferecem saberes, valores, regras às quais se ajustam dia após dia.

Para descrever e compreender a produção da inovação do ensino de gramática pelo professor em sala de aula, procuramos focalizar, nesse tecido, os fios que ligam o professor:

- a um coletivo de trabalho, ou seja, a um grupo de professores que apresenta características comuns;

- às prescrições que lhe são feitas, diretamente, por meio de documentos oficiais e, indiretamente, por meio de referências teórico-metodológicas sobre língua e ensino de língua vindas sobretudo da Linguística;

2 "Tarefa" (tâche), de acordo com Amigues (2004), refere-se ao que deve ser feito pelo professor em sala de aula em termos de objetivos e de procedimentos. 
- ao seu trabalho de construção de objetos (conteúdos de ensino) efetivamente ensinados em sala de aula;

- aos instrumentos semióticos mediadores dessa construção.

Para focalizar os fios que ligam o professor a um coletivo de trabalho, tomamos como referência as ideias defendidas por Amigues $(2002,2004) \mathrm{e}$ Faïta (2004) sobre a dimensão coletiva do trabalho do professor. Para Amigues (2002), cada professor pertence a vários coletivos: o da profissão, o da disciplina, o do estabelecimento de ensino, o da série, o da classe, entre outros. Esses coletivos, de acordo com o autor, se organizam de formas diversas e produzem regras de funcionamento que constituem uma resposta comum às prescrições e também o suporte a investimentos subjetivos constantes para responder àquilo que as prescrições não dizem e para fazer o melhor em uma zona de incerteza; esse engajamento pessoal é tanto mais forte quanto mais ele for sustentado por um coletivo de trabalho (AMIGUES, 2002). No caso dos coletivos do estabelecimento de ensino, da série e da classe, por exemplo, as relaçôes se estabelecem por meio de contatos cotidianos e repetidos, sejam esses contatos motivados pelo estabelecimento ou por afinidades interpessoais. Desse modo, "os professores, coletivamente, se autoprescrevem tarefas, que cada professor vai retomar e redefinir em sua classe ou suas classes" (AMIGUES, 2004, p. 43).

Mas, de acordo com Faïta (2004), há também práticas transversais características do professorado em seu conjunto, fora dos contatos cotidianos e repetidos. Um exemplo apresentado por esse autor é o de uma pesquisa desenvolvida por Saujat (2002) que propóe considerar a existência de um coletivo "iniciantes" no conjunto do corpo docente. Como explica Faïta (2004), essa é uma categoria de professores que apresentam traços comuns, independentemente dos lugares de lotação e exercício. Nos termos desse autor, os professores iniciantes têm em comum "o fato de compensarem - ou tentarem compensar - a insuficiência transitória de sua capacidade de tratar de situaçôes profissionais complexas mediante o desenvolvimento de recursos intermediários" (FAÏTA, 2004, p. 63). Ressalta-se, por exemplo, a forte dedicação dos iniciantes no domínio da classe (entradas e saída dos alunos, mudanças de lugar, regulação dos comportamentos dos alunos, tomadas de palavra, etc.). Isso nos permite supor, no dizer de Faïta (2004, p. 62), 
que a exposição a dificuldades semelhantes, o fato de encontrar obstáculos comparáveis na consecução dos programas e na realização das tarefas gere estratégias e condutas que transcendem limites espaçotemporais próprios do meio profissional localizado. (...) também se produzem, em uma esfera de atividade profissional como o ensino, trocas e circulação de idéias que ultrapassam os limites das situaçôes observáveis, e até mesmo formas de fazer mais ou menos difundidas na profissão, que não são, entretanto, formalizadas e discutidas. Isso implica a emergência de uma nova entidade, um ator coletivo que pode se moldar claramente, em função da semelhança de preocupações, de coerções reiteradas para a ação, sem que necessariamente realize escolhas e julgamentos explícitos, formalmente compartilhados e discursivizados.

Nesse sentido, em nossa investigação, consideramos um coletivo específico: o dos professores empenhados em inovar sua prática pedagógica de ensino de ensino de gramática, professores esses lotados em diferentes escolas de uma mesma Diretoria de Ensino. ${ }^{3}$ Para caracterizar esse coletivo, consideramos duas variáveis principais: os traços históricos comuns referentes tanto às informações pessoais e de formação e atuação profissional, sistematizadas a partir de um questionário respondido pelos interessados em participar da pesquisa, quanto a concepções e práticas desses professores explicitadas em seus depoimentos em uma intervenção que realizamos com o intuito de selecionar os participantes da pesquisa; e outros traços comuns que foram recuperados na análise das aulas dos professores.

Para focalizar os fios que ligam o professor às prescrições que lhe são feitas, nos baseamos nas noções de trabalho prescrito / trabalho realizado defendidas por Amigues (2002, 2004). Para esse autor, o trabalho prescrito (prescrições) refere-se aos aspectos institucionais e normativos, quer formais ou informais, que regem o trabalho do professor no seu dia-a-dia. As prescrições, de acordo com Amigues (2004), não servem apenas como desencadeadoras da ação do professor, são também constitutivas de sua atividade. Desse modo, as ações efetivamente realizadas pelo professor (trabalho realizado) não consistem apenas em seguir prescrições mas também em colocá-las à prova e redefini-las em função dos alunos, de imperativos ligados ao tempo, de reflexões realizadas durante a própria ação, dos instrumentos mobilizados, etc. Além disso, o autor ressalta o caráter vago das prescrições, no sentido de que elas dizem o que é

${ }^{3}$ Trata-se da Diretoria de Ensino de uma cidade da região noroeste do interior paulista. 
preciso ser feito, mas não como se deve fazê-lo; o que requer traduções e reelaborações pelo professor.

Um outro aspecto sobre as prescrições, salientado por Amigues (2002), é o fato de que elas difundem o discurso, no caso da França, dos inspetores ou formadores - especialistas que, com professores de diferentes categorias de ensino e representantes das associações culturais ou profissionais compóem os "Grupos Técnicos Disciplinares". Esses grupos são responsáveis pela elaboração dos programas escolares que, por sua vez, são retomados e discutidos no âmbito dos estabelecimentos escolares.

Já no Brasil, as prescrições advêm de uma cascata hierárquica: no nível nacional há a lei de Diretrizes e Bases, os PCN, depois as Propostas Curriculares estaduais e municipais, as quais são retomadas / repensadas, no âmbito de cada escola, nas orientações para o planejamento escolar e para a elaboração do plano de ensino do professor. Com relação às prescrições dirigidas ao professor de língua portuguesa do Ensino Fundamental II via textos oficiais, podemos dizer que, de modo geral, elas difundem os discursos de disciplinas da ciência Linguística, produzidos e divulgados sobretudo por linguistas. No Estado de São Paulo, o processo de elaboração e implementação da Proposta Curricular para o Ensino de Língua Portuguesa no Primeiro Grau (doravante PCLP), iniciado no final da década de 1970, envolvendo técnicos da Coordenadoria de Estudos e Normas Pedagógicas (CENP) e representantes de professores da rede pública estadual, foi subsidiado por especialistas de universidades do Estado - USP, UNESP, UNICAMP, PUC/SP -, em sua maioria linguistas (Cf. APARÍCIO, 1999). Com relação aos PCN, seu processo de elaboração, iniciado em 1995, que partiu da análise dos currículos vigentes nos estados e municípios de capitais do país, também envolveu especialistas de universidades principalmente do centro-sul, além de professores, técnicos e consultores nacionais e internacionais.

Para focalizar os fios que ligam o professor ao seu trabalho de construção dos objetos efetivamente ensinados na aula e aos instrumentos semióticos mobilizados na mediação dessa construção, nos apoiamos em estudos de Schneuwly (2000, 2005); Schneuwly, Dolz e Cordeiro (2005); Schneuwly e Wirthner (2004); Dolz, Moro e Pollo (2000) e outros pesquisadores do GRAFE (Groupe de Recherche pour Analyse du Français Enseigné), do Departamento de Didática de Línguas da Universidade de Genebra. Esses estudos propõem a construção de uma metodologia de análise dos objetos efetivamente ensinados em aulas de francês como língua materna, elegendo como unidade de análise os objetos efetivamente ensinados na aula, com 
atenção particular aos instrumentos semióticos mobilizados pelo professor na construção desses objetos. Um objeto efetivamente ensinado, para Schneuwly (2005), é o resultado de um processo de transposição didática interna (CHEVALLARD, 1991), ou seja, do processo em que os objetos a ensinar / objetos de ensino (conteúdos de ensino) transformam-se em objetos efetivamente ensinados em sala de aula. Esse processo, de acordo com Schneuwly (2000), implica uma dupla semiotização do objeto de ensino: de um lado, ele torna-se presente por meio das técnicas de ensino, materializado sob formas diversas (objetos, textos, folhas, exercícios, etc.) como objeto a ser ensinado, a ser semiotizado, a partir do qual novas significações podem e devem ser elaboradas pelos alunos; de outro lado, ele é focalizado como objeto sobre o qual aquele que tem a intenção de ensinar guia / orienta a atenção do aluno, apontando / mostrando as dimensóes essenciais desse objeto, por meio de procedimentos semióticos diversos. Esses dois processos - tornar presente o objeto a ensinar e apontar / mostrar as dimensões essenciais desse objeto -, assinala Schneuwly (2000), são indissociáveis e se definem mutuamente. Nesse sentido, esse autor define instrumentos semióticos como aqueles que permitem essa dupla semiotização do objeto de ensino. Nos termos de Schneuwly, (2000, p. 23), esses instrumentos são de dois tipos:

aqueles que asseguram o encontro /contato do aluno com o objeto a ensinar e aqueles que asseguram a orientação / direção da atenção do aluno. Os primeiros são, sobretudo, de ordem material (textos, exercícios, esquemas, objetos reais e muitas outras coisas), os segundos são, sobretudo, de ordem discursiva; mas o discurso pode igualmente produzir objetos a ensinar e permitir seu encontro / contato com os alunos, como também os instrumentos materiais podem assegurar, por formas específicas, a direção da atenção do aluno (tradução nossa). ${ }^{4}$

Esses instrumentos e os processos que eles envolvem, de acordo com Schneuwly (2005), são específicos de cada disciplina, dado que pressupóem a existência de uma tradição de práticas profissionais historicamente constituídas,

\footnotetext{
${ }^{4}(\ldots)$ ceux qui assurent la rencontre de l'élève avec l'objet et de ceux qui assurent le guidage d'attention. Les premiers sont plutôt de l'ordre du materiau (textes, exercices, schémas, objets réels, et mille autres choses), les deuxièmes plutôt de l'ordre du discours; mais les discours peut également produire des objets et permettre leur rencontre tout comme inversement du materiau peut assurer, par des formes spécifiques, le guidage de l'attention.
} 
as quais o professor (re)cria, (re)inventa em cada aula, a cada momento em que um objeto a ensinar torna-se um objeto efetivamente ensinado.

Desse modo, essa perspectiva de análise do trabalho do professor proposta por Schneuwly (2000, 2005), além de permitir um maior conhecimento de uma das dimensóes essenciais do trabalho do professor que é a dos instrumentos semióticos materiais (textos, exercícios, etc.) e discursivos (definições, explicações, exposições, instruções, etc.) mediadores da atividade de ensino, permite interpretar o trabalho do professor à luz da tradição e da evolução recente das práticas de ensino de língua materna, e evidenciar as formas, ao mesmo tempo constantes e variáveis, que tomam os objetos de ensino quando se tornam objetos ensinados na aula.

Em síntese, entendemos que esse percurso de construção dos pressupostos teóricos da pesquisa representa uma tentativa de evitar reduções que simplificariam demais nosso objeto de investigação - a produção, na sala de aula, da inovação no ensino de gramática.

\section{Metodologia e processo de geração dos dados}

Caracterizamos nosso trabalho como uma pesquisa qualitativointerpretativista de natureza etnográfica, pois, os dados foram gerados por meio de instrumentos associados à etnografia, tais como: anotações de campo, questionários, relatos, entrevistas pesquisador / professor, gravação em áudio de interaçōes pesquisador / professor e professor / alunos. Esses instrumentos foram utilizados nos diferentes momentos de interlocução que estabelecemos com os professores participantes da pesquisa. Ressaltamos ainda que os dados gerados foram confrontados com base na triangulação de dados que consiste, segundo Erickson (1989), na conjugação de diferentes fontes e tipos de dados com vistas a dar conta dos significados possíveis sobre o objeto em estudo e a garantir a validade da interpretação por parte do pesquisador.

Quanto ao processo de geração dos dados de pesquisa, foi desenvolvido entre junho de 2002 e junho de 2003 e deu-se de dois modos: em presença, ou seja, em encontros face a face com os professores participantes; e a distância, quando os próprios professores participantes gravaram suas aulas.

Os encontros face a face ocorreram em vários momentos. Em um primeiro momento, realizamos um encontro com 37 professores $^{5}$ de língua

\footnotetext{
${ }^{5}$ Esses professores foram convidados, por meio da Diretoria de Ensino, a participar
} de um encontro de oito horas, com direito a abono do dia de trabalho. 
portuguesa de escolas públicas estaduais jurisdicionadas à Diretoria de Ensino em questão. Nesse encontro, nossa intenção era gerar dados que nos permitissem identificar um coletivo de professores, isto é, um grupo de professores empenhados em inovar sua prática pedagógica de ensino de gramática. Em função disso, pedimos, inicialmente, aos professores que estivessem interessados em participar da pesquisa para responder a um questionário informativo. Esse questionário foi elaborado para a obtenção de informações de cunho mais geral ligadas à identificação dos professores (idade, sexo, período em que cursaram a licenciatura, tempo de experiência na docência, escolas e séries em que atuavam), e de informações mais específicas ligadas à formação e atuação desses profissionais (cursos de formação continuada frequentados, leituras realizadas, materiais utilizados nas aulas).

Nesse primeiro encontro, também realizamos uma intervenção, desenvolvendo a leitura e discussão de alguns textos ${ }^{6}$ que, além de terem em comum a busca do professor e / ou do estudante de Letras como interlocutor, caracterizam-se como obras de divulgação de novas concepções teóricometodológicas de ensino da língua, principalmente sobre aspectos relacionados ao ensino de gramática. Com isso, pretendíamos provocar reflexôes sobre o tema abordado nos textos e assim sensibilizar os professores para um maior engajamento nas discussões, pois interessavam-nos também observar como relacionavam o que liam com suas próprias concepçôes e práticas. Conforme pretendíamos, as reflexões teóricas e metodológicas trazidas por esses textos geraram muitas discussóes em que os professores expressaram suas opiniões, convicções, dúvidas e dificuldades em relação à inovação no ensino de gramática em sala de aula.

${ }^{6}$ Obedecendo a sequência das leituras, os textos selecionados foram os seguintes:

1- Sofrendo a gramática (a matéria que ninguém aprende) de Mário A. Perini (1997, p. 47-56);

2- Reflexão gramatical na prática pedagógica e Prática de análise lingüistica dos Parâmetros Curriculares Nacionais de Ensino Fundamental de 5a. a $8^{\text {a }}$ séries Língua Portuguesa (PCN) (1998, p.28-29/59-63);

3- Ensino de gramática $x$ reflexão sobre a língua de João Wanderley Geraldi (1996, p. 129-136);

4- Gramática reflexiva de Luiz Carlos Travaglia (1996, p.142-178);

5- A gramática: conhecimento e ensino de Maria Helena de Moura Neves (2000, p. 52-73). 
A partir dos dados gerados nesse primeiro encontro, identificamos alguns traços comuns entre 18 de 30 professores que responderam ao questionário informativo manifestando interesse em participar da pesquisa. São esses traços que consideramos para compor o coletivo de professores participantes:

- tinham cursado a Licenciatura Plena em Letras entre 1992 e 1999;

- tinham no mínimo um ano de experiência no ensino de língua portuguesa de $5^{\mathrm{a}}$ a $8^{\mathrm{a}}$ séries e / ou ensino médio, seja no ensino público e / ou particular;

- afirmavam continuar freqüentando cursos de capacitação na área de ensino de língua após a conclusão da licenciatura;

- afirmavam conhecer a PCLP e os PCNs;

- afirmavam estar tentando transformar sua prática em sala de aula;

- afirmavam organizar suas próprias aulas a partir da seleção de diversos materiais.

Assim, esses 18 professores foram convidados a participar de um segundo encontro para discussão dos procedimentos de gravação das aulas. Tendo em vista atender à decisão do grupo quanto a não participação do pesquisador na gravação das aulas, considerando que nossa presença iria interferir no comportamento do professor e dos alunos, comprometendo o andamento natural da aula, ficou estabelecido que os próprios professores gravariam as suas aulas de gramática, em situações "naturalistas", 7 obedecendo sua rotina normal de trabalho.

Por fim, apenas 7 professores se voluntariaram a gravar suas aulas e a continuar nos fornecendo informações sobre suas práticas. Os 7 professores, cujos nomes referidos neste trabalho são fictícios, gravaram uma aula cada um. Assim, os dados gerados a distância correspondem aos dados gerados na sala de aula, isto é, às 7 aulas de gramática gravadas pelos próprios professores.

Ressaltamos que, embora não tenhamos acompanhado presentemente as aulas dos professores nas escolas e não tenhamos elementos objetivos para avaliar o grau de representatividade das aulas gravadas em relação ao conjunto das aulas habitualmente ministradas por esses professores, temos conviç̧ão de que as aulas gravadas representam o que esses professores têm tentado construir cotidianamente na sala de aula.

${ }^{7}$ Referem-se a situações observadas em sua manifestação natural, sem qualquer modificação ou controle por parte dos atores envolvidos. 
Os outros encontros que tivemos com os professores participantes ocorreram, após o período de gravação das aulas, quando necessitamos obter mais informações sobre os dados de sala de aula já transcritos.

\section{Caracterização dos professores participantes da pesquisa}

A partir do conjunto dos dados relativos à identificação dos professores, gerados pelo questionário informativo, podemos caracterizar o grupo de participantes da pesquisa como sendo, em sua maioria, do sexo feminino (seis dos sete participantes), com idade entre 27 e 39 anos, formados em Letras entre 1995 e 1999; com experiência em sala de aula entre 2 e 7 anos em escolas públicas no ensino fundamental II.

Já a partir das informações sobre a formação e atuações profissionais desses professores, podemos caracterizá-los como profissionais que: frequentaram cursos de formação continuada após a Licenciatura em Letras; tiveram acesso às novas orientações teórico-metodológicas para o ensino de língua materna produzidas em diferentes disciplinas da Linguística, via cursos frequentados e/ou textos lidos oficiais ou de divulgação; não seguem um manual didático específico na aula, mas utilizam, dentre outros materiais, livros didáticos do Ensino Fundamental II ( $5^{\mathrm{a}}$. a $8^{\mathrm{a}}$. séries), sobretudo os avaliados e recomendados pelo MEC, para a preparação e desenvolvimento de suas aulas.

Finalmente, a partir dos dados gerados na intervenção, podemos afirmar que os professores participantes demonstram reconhecer as limitaçóes do ensino tradicional de gramática e a necessidade de assumir novas posturas em sala de aula, mas também demonstram ter dificuldade em relação ao que escapa à gramática tradicional. Esse reconhecimento, no entanto, não anula suas preocupações e suas dúvidas em relação às consequências da substituição da prática tradicional por uma prática centrada na reflexão linguística (eu tenho medo porque o meu aluno não está tendo a gramática sistematizada e o outro está... ai eu pergunto...quem vai se sair melhor?), bem como em relação às dificuldades para o desenvolvimento dessa nova prática (mas a gente tem que abrir mão de todos aqueles conceitos... a gente tem que partir de outros... / você está querendo mudar ai você vai num livro do Pasquale tão famoso tão conhecido né? gramática normativa).

${ }^{8}$ Exceto um professor, que foi formado pela Universidade Federal de Mato Grosso do Sul, todos os outros cursaram a Licenciatura em cursos noturnos oferecidos por instituições privadas da região. 
Além disso, os professores demonstram ter consciência dos seguintes aspectos:

- do caráter sucinto e amalgamado das propostas curriculares oficiais e da necessidade de aprofundamento de discussões sobre as noções veiculadas por esses documentos;

- da ideia da impossibilidade da transposição direta de conhecimentos teóricos para a sala de aula, e de que o domínio desses conhecimentos não é condição única nem suficiente para a inovação da prática em sala de aula;

- das deficiências dos livros didáticos em relação ao tratamento dado ao ensino de gramática;

- do poder de interferência dos comandos paragramaticais, ${ }^{9}$ bem como dos vestibulares e dos exames de avaliação oficiais como o SARESP, ${ }^{10}$ no processo de implementação de mudanças no ensino da língua na escola.

\section{Os modos como a inovação é produzida nas aulas de gramática}

Conforme já salientamos acima, os 7 professores participantes gravaram uma aula cada um. Essas aulas foram ministradas, em situações naturalistas, no ensino fundamental de $5^{\mathrm{a}}$. a $8^{\mathrm{a}}$. séries da rede pública estadual, entre o segundo semestre de 2002 e o primeiro semestre de 2003. Estamos denominando "aulas de gramática" as sessóes de aula apresentadas pelos professores como inovadoras. Desse modo, o conjunto das 7 aulas é composto de aulas de gramática que têm entre 30 e 40 minutos de duração. São aulas que fogem, de fato, do esquema tradicional de aula de gramática, isto é, não são aulas em que o elemento gramatical a ser estudado é introduzido por definiçōes e conceitos prontos, para posterior identificação e classificação pelo aluno, conforme já descrito pela literatura (NEVES, 1990; BATISTA, 1997; APARÍCIO, 1999; MORAES, 2000). São aulas em que os professores

\footnotetext{
9 Os comandos paragramaticais (CP) são, em sua forma "clássica", livros destinados ao público em geral (portanto, livros não-didáticos, no sentido de não serem manuais para o ensino convencional), escritos por autoproclamados "defensores da lingua portuguesa" (...) Em sua forma mais "moderna", os CP servem-se tanto dos meios de comunicação mais difundidos ao longo do século $X X$ - jornal, revista, rádio, televisão, telefone quanto das inovaçôes mais recentes no campo da produção e difusão de informaçôes o CD-ROM e a Internet (Bagno, 2000, p. 97).

${ }^{10}$ Sistema de Avaliação do Rendimento Escolar do Estado de São Paulo.
} 
procuram desenvolver atividades que exijam maior reflexão pelos alunos em relação ao estudo de categorias e funções gramaticais.

Tendo em vista visualizarmos o conjunto dessas aulas, elaboramos o quadro a seguir, em que apresentamos o objeto de ensino e o objetivo geral da aula de cada professor participante:

QUADRO

\begin{tabular}{|c|c|c|}
\hline \multicolumn{3}{|r|}{ resumo da aulas } \\
\hline Professor & Objeto de ensino & Objetivo geral \\
\hline ENI & Preposição "de" & $\begin{array}{l}\text { Reconhecer diferentes sentidos da preposição “de” em } \\
\text { sintagmas nominais, orações e fragmentos de texto. }\end{array}$ \\
\hline DANI & Pronomes pessoais & $\begin{array}{l}\text { Analisar e reconhecer, em um texto (poema), a função } \\
\text { referencial dos pronomes pessoais. }\end{array}$ \\
\hline OTO & Sujeito e vocativo & $\begin{array}{l}\text { Reconhecer diferenças entre sujeito e vocativo a partir da } \\
\text { análise de um caso de ambiguidade de sentidos provocada } \\
\text { pelo uso inadequado da vírgula na sentença de um texto: } \\
\text { Mãe só tem uma. }\end{array}$ \\
\hline ALINE & Sujeito & $\begin{array}{l}\text { Analisar e questionar, a partir da identificação do sujeito em } \\
\text { sentenças, a aplicabilidade de três definiçóes correntes de } \\
\text { sujeito. }\end{array}$ \\
\hline JADE & $\begin{array}{l}\text { Estrutura da sílaba } \\
\text { e divisão silábica }\end{array}$ & $\begin{array}{l}\text { Reconhecer a importância do estudo de menores unidades } \\
\text { da língua para a compreensão e produção de textos. }\end{array}$ \\
\hline DIVA & Substantivo & $\begin{array}{l}\text { Reconhecer, a partir da análise de um texto construído } \\
\text { somente com substantivos ("Circuito Fechado"), a função } \\
\text { dos substantivos na construção da coerência do texto. }\end{array}$ \\
\hline CARLA & $\begin{array}{l}\text { Adjetivo, locução } \\
\text { adjetiva e oração } \\
\text { adjetiva }\end{array}$ & $\begin{array}{l}\text { Substituir locuções adjetivas (por exemplo: amor de mãe) } \\
\text { ou oraçôes adjetivas (por exemplo: que tem coragem) por } \\
\text { adjetivos (por exemplo: materno ou corajoso) e reconhecer, } \\
\text { em sentenças ou fragmentos de texto, que o uso de uma } \\
\text { estrutura ou de outra (locução adjetiva / adjetivo ou } \\
\text { adjetiva / adjetivo), embora sejam correspondentes, têm } \\
\text { efeitos de sentido diferentes. }\end{array}$ \\
\hline
\end{tabular}

O esquema acima demonstra que os professores continuam trabalhando com categorias da gramática tradicional, mas a inovação se produz, sobretudo, pela introdução de aspectos de descrição e de tratamento didático do objeto de ensino difundidos por textos científicos ou de divulgação produzidos por especialistas da área ou por documentos oficiais. 
Observando o conjunto dessas aulas, identificamos três modos significativos de produção da inovação pelos professores:

1) inclusão do nível semântico-pragmático na análise de categorias da gramática tradicional;

2) questionamento do modo de categorização da gramática tradicional a partir de procedimentos de descrição / análise disseminados pela Linguística;

3) contextualização do estudo de categorias da gramática tradicional a partir da explicitação dos procedimentos de descrição / análise dessas unidades.

O primeiro modo é o mais recorrente, é o adotado nas aulas das professoras ENI, DANI, OTO, DIVA e CARLA. O segundo modo é o que pode ser evidenciado na aula da professora ALINE e o terceiro modo na aula da professora JADE. Sendo assim, para a análise, selecionamos 3 aulas: a aula da professora ENI, representativa do primeiro modo, e as aulas das professoras ALINE e $\mathrm{JADE}$, as únicas que representam, respectivamente, o segundo e terceiro modo.

Para a descrição da organização global das 3 aulas sob análise, bem como para a delimitação das unidades de análise dessas aulas, adotamos as contribuições dos estudos de Matencio (2001) sobre as unidades constituintes de uma aula. Para essa autora, "uma aula caracteriza-se como um gênero atualizado em um evento de interação cuja materialidade reflete uma organização social relativamente estável e uma configuração temática predominantemente didática" (MATENCIO, 2001, p. 99).

Nesse sentido, para a autora, as dimensões interacional e didática são igualmente importantes. Assim, com base em categorias conversacionais e textuais, Matencio (2001) procura descrever a organização e o funcionamento das diferentes unidades que constituem uma aula, explicitando tanto as relações de articulaçãoo e hierarquização dessas unidades quanto de suas especificidades e funções. Desses estudos, interessam-nos as noçōes de sequências didáticodiscursivas, atividades e tarefas didáticas.

Segundo Matencio (2001), a atividade didática é uma operação de ensino / aprendizagem complexa que engloba as tarefas, e essas têm como objetivo justamente realizar a atividade. Considera a autora que o estudo de um texto, por exemplo, é uma atividade que corresponde a um módulo de ensino que pode envolver uma série de atividades, como a leitura, a interpretação e a análise. A atividade de leitura, por sua vez, pode ser desmembrada em tarefas, por exemplo, a leitura individual e silenciosa, a leitura em voz alta. Assim, entendemos que, em nosso caso, o estudo de um conteúdo gramatical é um módulo de ensino que envolve uma série de atividades constituídas por tarefas. 
Já as sequências didático-discursivas, para Matencio (2001), são unidades da aula cujos limites são determinados pela coerência relativa aos focos discursivos e ao desenvolvimento das tarefas que constituem a(s) atividade(s) proposta(s). Nesse sentido, o primeiro procedimento para a análise de uma aula é segmentar as sequências didático-discursivas, identificando as atividades e as tarefas que as constituem.

Com base nessa proposta, apresentamos, nos quadros a seguir, a organização global das aulas consideradas para análise, evidenciando a disposição das atividades e tarefas e as sequências didático-discursivas configuradas em cada atividade realizada.

\section{QUADRO I}

Esquematização da organização global da aula 1Preposição de- Profa. ENI- $8^{\text {a }}$. série

\begin{tabular}{|c|c|c|}
\hline Sequências & Atividades & Tarefas \\
\hline I & $\begin{array}{l}\text { 1- Leitura e discussão do texto de Mário } \\
\text { Perini (1997) “As gravatas de Mário } \\
\text { Quintana”, que versa sobre a importância } \\
\text { de informações extralinguísticas para a } \\
\text { identificação de diferentes sentidos da } \\
\text { preposição de em enunciados que } \\
\text { apresentam a mesma estrutura sintática. }\end{array}$ & $\begin{array}{l}\text { - Leitura em voz alta do texto por um } \\
\text { aluno; } \\
\text { - Identificação da "moral da história" do } \\
\text { texto lido; } \\
\text { - Análise e discussão de exemplos trazidos } \\
\text { pelo texto lido; }\end{array}$ \\
\hline II & $\begin{array}{l}\text { 2- Resolução, pelos alunos, com a profes- } \\
\text { sora, de um teste extraído de exame vesti- } \\
\text { bular, }{ }^{11} \text { que solicita a identificação da } \\
\text { relação de sentido "nocional" estabelecida } \\
\text { pela preposição de no fragmento de texto } \\
\text { de uma das alternativas do exercício. }\end{array}$ & $\begin{array}{l}\text { - Leitura pela professora do enunciado da } \\
\text { questão; } \\
\text { - Observação da relação "nocional" } \\
\text { expressa pela preposição de no exemplo } \\
\text { apresentado no enunciado da questão; } \\
\text { - Identificação das relações de sentido } \\
\text { expressas pela preposição de nos fragmentos } \\
\text { de cada uma das alternativas, por meio da } \\
\text { estratégia de exclusão das alternativas } \\
\text { incorretas para se chegar à correta; }\end{array}$ \\
\hline
\end{tabular}

11 (FUVEST/1995) Ao ligar dois termos de uma oração, a preposição pode expressar, entre outros aspectos, uma relação temporal, espacial ou nocional. Nos versos: "Amor total e falho... Puro e impuro... Amor de velho adolescente...", a preposição de estabelece uma relação nocional. Essa mesma relação ocorre em:

a) "Este mundo de hotel é um fim de mundo."

b) "A quem sonha de dia e sonha de noite, sabendo todo sonho vão."

c) "depois fui pirata mouro, flagelo da Tripolitânia."

d) "Chegarei de madrugada, quando cantar a seriema."

e) "Só os roçados da morte compensam aqui cultivar." 


\begin{tabular}{|c|c|c|}
\hline III & $\begin{array}{l}\text { 3- Resolução, somente pelos alunos, de } \\
\text { um outro teste extraído de exame } \\
\text { vestibular, }{ }^{12} \text { que solicita a identificação da } \\
\text { relação de sentido de "causa" expressa } \\
\text { pela preposição de em um fragmento de } \\
\text { texto literário. }\end{array}$ & $\begin{array}{l}\text { - Leitura pela professora do enunciado } \\
\text { da questão; } \\
\text { - Identificação apenas da alternativa. }\end{array}$ \\
\hline \multicolumn{3}{|c|}{$\begin{array}{l}\text { QUADRO II } \\
\text { da organização global da aula 2- Sujeito- } \\
\text { Profa. ALINE- 8a. série }\end{array}$} \\
\hline Sequências & Atividades & Tarefas \\
\hline I & $\begin{array}{l}\text { 1- Análise e discussão da aplicabilidade } \\
\text { da definição "sujeito é o termo sobre o } \\
\text { qual se faz uma declaração" na } \\
\text { identificação do sujeito de } 8 \text { sentenças } \\
\text { trazidas pela professora. }{ }^{13}\end{array}$ & $\begin{array}{l}\text { - Apresentação, oralmente pelos alunos, } \\
\text { das definições de sujeito que eles } \\
\text { recordam já terem sido estudadas em } \\
\text { séries anteriores; } \\
\text { - Apresentação na lousa, pela professora, } \\
\text { da primeira definição de sujeito a ser } \\
\text { discutida e das } 8 \text { sentenças a serem } \\
\text { analisadas; } \\
\text { - Realização, oralmente pelos alunos, } \\
\text { com auxílio da professora, de exercícios } \\
\text { de identificação do sujeito de cada uma } \\
\text { das sentenças apresentadas, com base } \\
\text { na definição de sujeito em questão. }\end{array}$ \\
\hline
\end{tabular}

12 (FUVEST/1999) A carruagem parou ao pé de uma casa amarelada, com uma portinha pequena. Logo à entrada um cheiro mole e salobro enojou-a. A escada, de degraus gastos, subia ingrememente, apertada entre paredes onde a cal caía, e a umidade fizera nódoas. No patamar da sobreloja, uma janela com um gradeadozinho de arame, parda do pó acumulado, coberta de teias de aranha, coava a luz suja do saguão. E por trás de uma portinha, ao lado, sentia-se o ranger de um berço, o chorar doloroso de uma criança. (Eça de Queirós, O primo Basilio)

O segmento do texto em que a preposição de estabelece uma relação de causa é: a-ao pé de uma casa amarelada

b-escada, de degraus gastos

c-gradeadozinho de arame

d-parda do pó acumulado

e-luz suja do saguão.

${ }^{13}$ As sentenças são:

1-Carlinhos corre como um louco.

2-Carlinhos machucou Camilo.

3-Esse bolo eu não vou comer. 


\begin{tabular}{|c|c|c|}
\hline II & $\begin{array}{l}\text { 2- Análise e discussão da aplicabilidade } \\
\text { da definiçãao "sujeito é o elemento que } \\
\text { pratica a ação" na identificação do sujeito } \\
\text { das mesmas } 8 \text { sentenças da atividade } \\
\text { anterior. }\end{array}$ & $\begin{array}{l}\text { - Apresentação na lousa, pela professora, } \\
\text { da segunda definição de sujeito a ser } \\
\text { discutida; } \\
\text { - Realização, oralmente pelos alunos, com } \\
\text { auxílio da professora, de exercícios de } \\
\text { identificação do sujeito das mesmas } \\
\text { sentenças já apresentadas, com base na } \\
\text { outra definição de sujeito em questão. }\end{array}$ \\
\hline III & $\begin{array}{l}\text { 3- Análise e discussão da aplicabilidade } \\
\text { da definição "sujeito é o termo da oração } \\
\text { com o qual o verbo concorda" na identi- } \\
\text { ficação do sujeito das mesmas } 8 \text { sentenças } \\
\text { das atividades anteriores. }\end{array}$ & $\begin{array}{l}\text { - Apresentação na lousa, pela professora, } \\
\text { da terceira definição de sujeito a ser } \\
\text { discutida; } \\
\text { - Realização, oralmente pelos alunos, } \\
\text { com auxílio da professora, de exercícios } \\
\text { de identificação do sujeito das mesmas } \\
\text { sentenças já apresentadas, com base na } \\
\text { terceira definição de sujeito. }\end{array}$ \\
\hline IV & $\begin{array}{l}\text { 4- Produção escrita pelos alunos, a } \\
\text { partir das análises e discussões } \\
\text { desenvolvidas nas atividades anteriores, } \\
\text { sobre a definição mais adequada para a } \\
\text { identificação do sujeito em português. }\end{array}$ & $\begin{array}{l}\text { - Apresentação na lousa, pela professora, } \\
\text { da questão: "Considerando a discussão } \\
\text { que desenvolvemos a partir das três } \\
\text { definições de sujeito, na sua opinião, qual } \\
\text { dessas definições é a mais adequada para } \\
\text { a identificação do sujeito em português?"; } \\
\text { - Redação de um texto argumentativo, } \\
\text { individualmente, pelos alunos, em } \\
\text { resposta à questão apresentada pela } \\
\text { professora. }\end{array}$ \\
\hline
\end{tabular}

4-A vidraça quebrou.

5-Vendi meu jegue.

6-Roubaram meu carro.

7-Em Belo Horizonte chove um bocado.

8-Marivânia chegando, a farra vai começar. 
QUADRO III

Esquematização da organização global da aula 3- Profa. JADE- 5a ${ }^{\text {a }}$ série

\begin{tabular}{|c|c|c|}
\hline Sequências & Atividades & Tarefas \\
\hline I & $\begin{array}{l}\text { Explicitação, pela professora, dos proce- } \\
\text { dimentos de descrição / análise do objeto } \\
\text { a ser ensinado na aula: sílabas em } \\
\text { português. }\end{array}$ & $\begin{array}{l}\text { - Reflexão, a partir de analogias e exemplos } \\
\text { mobilizados pela professora e por um } \\
\text { aluno, sobre como e por que estudar } \\
\text { unidades menores da língua fora de } \\
\text { contextos de uso. }\end{array}$ \\
\hline II & $\begin{array}{l}\text { Descrição e análise da estrutura da sílaba } \\
\text { em português. }\end{array}$ & $\begin{array}{l}\text { - Observação das sílabas que compõem } \\
\text { uma palavra retirada do texto estudado } \\
\text { na aula de leitura e compreensão de } \\
\text { texto; } \\
\text { - Leitura, pela professora, da definição de } \\
\text { sílaba apresentada em uma apostila } \\
\text { utilizada na aula; } \\
\text { — Reflexão sobre o mecanismo de articula- } \\
\text { ção de unidades da língua em diferentes } \\
\text { níveis; } \\
\text { - Reflexão sobre diferenças entre fala e } \\
\text { escrita e sobre a importância do domínio } \\
\text { da escrita formal. }\end{array}$ \\
\hline III & $\begin{array}{l}\text { Análise e discussão de um exemplo real em } \\
\text { que um erro de divisão silábica compro- } \\
\text { mete a leitura do texto. }{ }^{14}\end{array}$ & $\begin{array}{c}\text { - Reflexão sobre a importância do estudo } \\
\text { das sílabas e da divisão silábica para a } \\
\text { produção e compreensão de textos. }\end{array}$ \\
\hline
\end{tabular}

A esquematização da organização global das três aulas representada nos quadros acima evidencia que cada aula segue um percurso diferente de construção do objeto ensinado, em função dos diferentes instrumentos mobilizados na mediação dessa construção. $\mathrm{Na}$ aula 1 , a professora parte da leitura e discussão de um texto de um linguista e propóe a resolução de duas questôes de vestibular. $\mathrm{Na}$ verdade, a aula se organiza em função desses três instrumentos, isto é, cada um compõe uma sequência didático-discursiva da aula. Já na aula 2 , os instrumentos mediadores da construção do objeto ensinado são três definições desse objeto e 8 sentenças. A aula é estruturada em função dessas três definições, que são analisadas e discutidas, cada uma, em uma sequência didático-discursiva. A aula 3, por sua vez, também se organiza em função dos principais instrumentos mediadores da construçáo do objeto

${ }^{14}$ O exemplo é: VENDE ESTE RCO, em lugar de "Vende esterco". 
ensinado. Nessa aula, a professora parte da explicitação dos procedimentos de descrição / análise do objeto a ser ensinado, apresenta uma definição desse objeto e analisa um exemplo que, por meio do erro que ele apresenta, tematiza o objeto de ensino da aula. Cada um desses principais instrumentos mediadores da construção do objeto ensinado - a explicitação dos procedimentos de descrição / análise do objeto a ser ensinado, a definição desse objeto, o exemplo que apresenta incorreção - compõe uma sequência didático discursiva da aula.

Embora os percursos de construção do objeto ensinado sejam diferentes, há uma estratégia comum às atividades e tarefas realizadas nas aulas: quase todas são realizadas oralmente. A única exceção é a atividade realizada na sequência IV da aula 2 - uma produção escrita pelos alunos.

Além disso, todas as atividades desenvolvidas nas aulas, como evidenciam os quadros acima, demandam o trabalho de observação e reflexão pelo aluno voltadas para a explicitação de aspectos relativos a categorias gramaticais, que são os objetos ensinados nas aulas, e/ou sobre o uso dessas categorias nos exemplos mobilizados nessas aulas, sejam textos, fragmentos de texto ou sentenças. Apenas uma tarefa da aula 3 (observação das sílabas que compõem uma palavra retirada do texto estudado na aula de leitura e compreensão do texto) tem a palavra como unidade de análise. Nenhuma atividade ou tarefa realizada demanda a pura a simples identificação e / ou classificação da categoria gramatical em estudo.

Em uma análise mais detalhada e minuciosa do desenvolvimento dessas três aulas procuramos:

- identificar e descrever os objetos efetivamente ensinados, ou seja, os objetos de estudo construídos pelos professores;

- identificar e descrever os instrumentos semióticos materiais e discursivos mediadores da construção dos objetos efetivamente ensinados;

- descrever e analisar como esses objetos são categorizados e recategorizados pelos professores no decorrer da aula, como esses objetos vão sendo transformados no decorrer da aula.

Os resultados dessa análise evidenciaram que os diferentes modos de inovação produzidos nessas aulas são constituídos por uma interrelação de atividades e práticas múltiplas e heterogêneas mediadas por instrumentos semióticos discursivos e materiais também heterogêneos. No caso da aula 1, ao tentar alinhar modos de análise mais inovadores aos mais tradicionais, trazidos pelos diferentes instrumentos materiais mobilizados na aula (texto de 
Perini e exercícios de vestibular), a professora acaba focalizando as variações de sentido estabelecidas pela preposição $d e$, sem distinguir explicitamente os dois níveis de interpretação semântica (o que requer conhecimentos linguísticos e o que requer conhecimentos extralinguísticos) levados em conta nas atividades de atribuição de sentidos à preposição de desenvolvidas na aula, mas também sem se prender às diferentes formas de classificação desses sentidos, oriundas de conflitos teórico-metodológicos existentes não somente entre a gramática e a linguística mas entre vertentes da própria linguística. Desse modo, o trabalho realizado pela professora ENI contempla uma articulação que o trabalho prescrito (os textos oficiais), bem como textos de divulgação produzidos por especialistas na área, não contempla: a articulação entre a necessidade de se ensinar gramática na escola, a busca da inovação com base em modelos científicos diversos de descrição e tratamento metodológico do objeto de ensino e a imposição do vestibular.

No caso da aula 2, a professora ALINE produz a inovação buscando desenvolver uma prática de análise de fatos da língua baseada em modelos científicos de descrição desses fatos, ou seja, em modelos que envolvem o raciocínio lógico, a coerência no uso de critérios de análise, tal como prescrevem os documentos oficiais. Os PCN, por exemplo, nas propostas para o desenvolvimento das atividades de análise linguística na sala de aula, sugerem que o professor construa com seus alunos um corpus que leve em conta a relevância, a simplicidade, bem como a quantidade de dados, para que o aluno possa perceber o que é regular; propicie a análise do corpus, promovendo o agrupamento dos dados a partir dos critérios construídos para apontar as regularidades observadas; solicite a organização e registro das conclusões a que os alunos tenham chegado. Lembramos que essa última sugestão também é acolhida pela professora no desenvolvimento da quarta atividade da aula (ver QUADRO II, sequência IV) correspondente à última sequência didáticodiscursiva da aula.

Mas o trabalho efetivamente realizado pela professora ALINE, assim como o trabalho realizado pela professora ENI, na aula 1, contempla articulaçóes que o trabalho prescrito não contempla. Mais especificamente, $o$ trabalho da professora ALINE contempla articulações entre categorizações da linguística, da gramática tradicional e do conhecimento gramatical implícito. $O$ resultado disso foi a construção de um objeto ensinado cujas características (traços) são consideradas pela linguística, pela gramática tradicional e pela gramática implícita. Nessa construção, ora a professora não tematiza traços 
considerados pela gramática tradicional, ora não tematiza traços considerados pela linguística, e os traços da gramática implícita vão emergindo à medida que se chega à "melhor" definição de sujeito - o objeto efetivamente ensinado na aula. Isso nos faz lembrar o que Schneuwly (2000) diz a respeito do papel dos instrumentos semióticos na mediação da construção dos objetos ensinados na aula: há os instrumentos que asseguram o encontro / contato do aluno com objeto a ensinar - principalmente os de ordem material (textos, exercícios, esquemas, objetos reais) - e há os que asseguram a orientação / direção do olhar do aluno para a dimensão que se quer ressaltar do objeto a ensinar principalmente os de ordem discursiva (explicações, definições, exposições, instruçōes).

Nesse sentido, o exercício elaborado pela professora ALINE, a seleção das sentenças para análise, a ordem das sentenças, a ordem em que as definições de sujeito foram analisadas, bem como as elaborações discursivas e metadiscursivas mobilizadas pela professora e alunos no decorrer da aula, como instrumentos semióticos exerceram, de fato, esses papéis apontados por Schneuwly (2000), na construção do objeto ensinado na aula e no modo como foi construído.

Já na aula 3, a inovação produzida pela professora JADE é a contextualização do estudo de unidades menores da língua (sílabas, palavras) a partir da explicitação dos procedimentos de descrição / análise dessas unidades. Em outras palavras, a professora procura desenvolver um estudo de unidades menores da língua de tal forma que não se compreenda essa atividade como uma prática de ensino de gramática tradicional, e sim como uma prática de descrição / análise de elementos linguísticos que, embora devam / possam ser analisados fora de um contexto, só adquirem verdadeiro sentido quando estão em funcionamento na língua. Assim, a professora justifica sua atitude, por meio de analogias, comparando o trabalho do cientista ao estudar as células fora do corpo humano com o trabalho do professor de estudar as palavras fora do texto. Em síntese, nessa aula, a professora considera o texto como unidade da análise linguística, mas não abdica do conhecimento da gramática tradicional (a gente vai voltar a ver um pouquinho essas tais de silabas para a gente tentar entender a acentuação de algumas palavras); da noção de erro (já pensou um dia quando vocês estiverem precisando fazer um cartaz e pregar e escrever o cartaz errado?); e da noção pedagógica de se aplicar regras em exercícios (quem conseguir ver uma placa...alguma coisa bem absurda assim...de separação de sílaba...de ortografia... de acentuação errada tá? traz que a gente vai tá analisando as regras...qual é que a gente poderia aplicar aí...) 
Enfim, os resultados da análise dessas 3 aulas evidenciam que a produção da inovação na aula de gramática é um espaço dinâmico que não apresenta fronteiras nítidas entre o inovador e o tradicional, e sim uma zona de "contínuo embaralhamento do que se apresenta como separado e excludente nos discursos de autoridade sobre língua(gem) e ensino, sobretudo na academia e na mídia” (SIGNORINI, 2007, p. 211).

Acreditamos que a explicitação desse espaço pode contribuir para os estudos de formação do professor, na medida que permite colocar em discussão a ideia comumente aceita, em cursos de formação inicial e continuada de professores, da incompatibilidade / incongruência entre princípios teóricometodológicos da gramática tradicional e da Linguística.

\section{Conclusão}

$\mathrm{Na}$ análise dos diferentes modos como a inovação é produzida nas aulas pelos professores participantes de nossa pesquisa, identificamos o fenômeno apontado por Faïta (2004), a que nos referimos na segunda seção deste artigo, sobre as práticas transversais características de um coletivo de professores, práticas essas que transcendem os limites espaço-temporais e que não são explicitadas e discutidas. Trata-se, de acordo com esse autor, das formas de fazer de um ator coletivo que se molda, em função da semelhança de preocupações, por exemplo, em nosso caso, as respostas comuns dos professores participantes, sem que necessariamente eles tenham realizado escolhas e julgamentos explícitos formalmente compartilhados e discursivizados, às mesmas prescrições que lhe são feitas. No caso de nossa pesquisa, as análises das aulas evidenciam que professores empenhados em inovar sua prática pedagógica de ensino de gramática apresentam, em seu trabalho em sala de aula, os seguintes traços comuns:

- desenvolvem a análise linguística somente com categorias da gramática tradicional, ainda que as demandas de inovação proponham também o trabalho com outras categorias, como as da gramática funcional e as da linguística de texto, por exemplo;

- para o estudo de categorias da gramática tradicional lançam mão de modos de descrição / análise disseminadas pela linguística, focalizando sobretudo a dimensão semântica da língua, além da dimensão morfossintática.

Desse modo, acreditamos ser possível levantar a hipótese de que o coletivo de professores que estão tentando inovar sua prática de ensino de 
gramática produz, independentemente das vontades e intenções individuais, algumas respostas comuns às demandas de inovação. Além disso, a nosso ver, as respostas produzidas pelos professores paulistas, em um momento pósPCN, visam principalmente atender às demandas de inovação trazidas há duas décadas pela PCLP.

Evidentemente, não podemos generalizar, afirmando que os traços comuns que identificamos nas aulas analisadas em nosso trabalho estão presentes nas aulas de todos os professores do Estado de São Paulo que estão buscando inovar sua prática de ensino de gramática. Mas, é possível vislumbrar as dificuldades que esses professores enfrentam ao desenvolverem o árduo trabalho de articulação dos discursos oficiais inovadores sobre a língua e ensino de língua, nem sempre compatíveis entre si e nem sempre compatíveis com as tradições escolares.

É a explicitação desse trabalho do professor, ou seja, desses modos individuais e coletivos de resolver um mesmo problema - produzir a inovação no ensino de gramática - que pensamos ser a contribuição desta investigação para os estudos sobre formação de professores de língua materna. Pois esses modos de agir, muitas vezes, não são reconhecidos, nem mesmo pelos próprios professores. Daí a importância de se reconhecer, de se compartilhar, esses modos de ação nas situações em que, de fato, ocorrem, para irmos além da identificação dos problemas que dificultam ou impedem a produção da inovação em sala de aula.

\section{Referências}

AMIGUES, R. L'eiseignement comme travail. In: BRESSOUX, P. (Ed.). Les stratégies d'enseignement en situation d'interaction. Programme Ecole et Sciences Cognitives, 2002. p. 243-262.

AMIGUES, R. Trabalho do professor e trabalho de ensino. In: MACHADO, A.R. (Org.). O Ensino como trabalho- uma abordagem discursiva. Londrina: Eduel, 2004.

APARÍCIO, A. S. M. A renovação do ensino de gramática no primeiro grau no Estado de São Paulo. 1999. Dissertação (Mestrado) Unicamp/IEL, Campinas, 1999.

BAGNO, M. Dramática da língua portuguesa-Tradição gramatical, mídia \& exclusão social. São Paulo: Loyola, 2000.

BATISTA, A.A.G. Aula de Português: discurso e saberes escolares. São Paulo: Martins Fontes, 1997. 
CHEVALLARD, Y. La transposition didactique. Du savoir savant au savoir enseigné. Grenoble: La Pensée Sauvage, 1991.

DOLZ, J.; MORO, C.; POLLO, A. Le débat régulé: De quelques outils et leurs usages dans l'aprentissage. Repères, n. 22, p. 39-59, 2000.

ERICKSON, F. Metodos Cualitativos de investigación sobre la enseñanza. In: WITTROCK, M. C. (Org.). La investigación de la enseñanza. Barcelona: Paidós, 1989. p.195-301.

FAÏTA, D. Gêneros de discurso, gêneros de atividade, análise da atividade do professor. In: MACHADO, A.R. (Org.). O Ensino como trabalho- uma abordagem discursiva. Londrina: Eduel, 2004.

GERALDI, J. W. Linguagem e ensino - Exercícios de militância e divulgação. Campinas: Mercado de Letras, 1996.

MATENCIO, M.de L. M. Estudo de língua falada e aula de lingua materna. Campinas: Mercado de Letras, 2001.

MORAES, E. M. M. A gramática na aula de Português. 2000. Dissertação (Mestrado) - Faculdade de Letras da UFMG, Belo Horizonte, 2000.

NEVES, M. H. de M. A gramática: conhecimento e ensino. In: AZEREDO, J.C. Lingua Portuguesa em debate: conhecimento e ensino. Petrópolis: Vozes, 2000. p. 52-73.

NEVES, M. H. de M. Gramática na escola. São Paulo: Contexto, 1990.

PERINI, M.A. Sofrendo a gramática. São Paulo, Ática, 1997.

ROJO, R. Os PCNs, as práticas de linguagem (dentro e fora da sala de aula) e a formação de professores. In: ROJO, R. (Org.). A prática de linguagem em sala de aula; praticando os PCNs. Campinas: Mercado de Letras, 2000. p. 7-11.

SAUJAT, F. Ergonomie de l'activité enseignante et développement de l'expérience professionelle. 2002. Thése pour le docotrat en Sciences de l'Education.

SAUJAT, F. O trabalho do professor nas pesquisas em educação: um panorama. In: MACHADO, A. R. (Org.). O Ensino como trabalho - uma abordagem discursiva. Londrina: Eduel, 2004.

SIGNORINI, I. Significados da inovação no ensino de lingua portuguesa e na formação de professores. Campinas: Mercado de Letras, 2007.

SCHNEUWLY, B. Les outils de l'enseignant: un essai didactique. Repères, n. 22, p.19-38, 2000.

SCHNEUWLY, B. Le travail de l'enseignant et l'objet enseigné. Palestra proferida no IEL/Unicamp, 2005. 
SCHNEUWLY, B.; DOLZ, J.; CORDEIRO, G. S. A la recherche de l'óbjet enseigné: une demarche multifocale. Texto mimeog. 2005.

SCHNEUWLY, B.; WIRTHNER, M. Variabilité et contrinte dans la construction des significations d'un objet d'enseignement. L'effet d'un outil pour enseigner le résumé d'un texte informatif. In: MORO, C.; RICKENMANN, R. (Ed.). Situation éducative et significations. Bruxelles: De Boeck \& Larcier, p. 107-133, 2004.

TRAVAGLIA, L. C. Gramática e interação: uma proposta para o ensino de gramática no $1^{\circ}$. e $2^{\circ}$. grau. São Paulo: Cortez, 1996.

Recebido em 2 de julho de 2008. Aprovado em 15 de maio de 2009. 